\title{
GAIA Level 4 Intrapartum Stillbirth
}

National Cancer Institute

\section{Source}

National Cancer Institute. GAIA Level 4 Intrapartum Stillbirth. NCI Thesaurus. Code C128025.

GAIA Level 4 Intrapartum Stillbirth is defined by two criteria: first, a report of stillbirth, but the fetus is unavailable for physical examination after birth so no objective assessment can be made; second, maternal information is insufficient to assess gestational age. 